ANUARIO MUSICAL, N. ${ }^{\circ} 66$

enero-diciembre 2011, 211-234

ISSN: 0211-3538

\title{
El movimiento wagneriano en Murcia (1879-1922)
}

\author{
WAGNERIAN MOVEMENT IN MURCIA (1879-1922)
}

\author{
Enrique Encabo Fernández \\ Universidad de Murcia
}

\section{Resumen:}

El movimiento wagneriano en Murcia tuvo que superar algunas reticencias iniciales. A pesar de ello, revistió las mismas características que en otros lugares: movimiento burgués, urbano y ligado a la idea de modernidad y progreso. Podemos distinguir dos etapas en el movimiento wagneriano en Murcia; una primera, en la que Wagner se lee más que se escucha; esta primera etapa culmina con la representación en Murcia de la ópera Lohengrin en 1890. A partir de este momento, comienza la segunda etapa, en la que los murcianos tienen la oportunidad de disfrutar un Wagner más sinfónico que operístico, gracias a la acción de las agrupaciones musicales de la ciudad (bandas y grupos de cámara) y los conciertos (a partir de 1910) de la Orquesta Sinfónica de Madrid.

\section{Palabras Clave:}

Wagner; Murcia; Siglo xIx; Ópera; Prensa; Crítica musical.

\begin{abstract}
:
The Wagnerian movement in Murcia had to overcome some initial resistance. Nonetheless, this movement would have the same characteristics as in other places: a bourgeois, urban movement linked to the idea of modernity and progress. Two stages can be distinguished in the assimilation of Wagnerian music in Murcia. The first stage, in which Wagner's music is more often read than played; this initial phase would end with the representation in 1890 of the opera Lohengrin in Murcia. In the second stage, the audience in Murcia would have the opportunity to enjoy a more symphonic Wagner thanks to the work of symphonic musical ensembles (bands and chamber groups) and the concerts offered (from 1910) by the Orquesta Sinfónica de Madrid.
\end{abstract}

\section{Keywords:}

Wagner; Murcia; $19^{\text {th }}$ Century; Opera; Press; Critical Review. 


\section{LOS INICIOS: LAS CAMPAÑNAS PROPAGANDÍSTICAS (1879-1898)}

Es bien sabido que la recepción y consolidación de la música de Wagner en Europa y España no fue un fenómeno sencillo. En el caso de la ciudad de Murcia, a las dificultades que encontró "la música del porvenir" en el resto de urbes (hegemonía del repertorio italiano y francés, calificativos como música "difícil”, "árida",...), hay que añadir la falta de un coliseo operístico (el Teatro Romea tan solo ofrecía una breve temporada de ópera de una o dos semanas de duración, lo que provocaba una falta de tradición lírica en el público) y la aparición tardía de una burguesía con aspiraciones culturales e intelectuales que impulsara la implantación de los nuevos artefactos artísticos. Hasta mediados de la década de 1870, no encontramos consolidado un grupo cultural que, a través de diversos medios (tertulias, veladas artísticas, prensa,...), fomente la modernización de las instituciones de la ciudad y la región, reclame una vida artística al nivel de las grandes ciudades del país, y provoque una actividad cultural (ligada al regionalismo) que servirá de base para la configuración de la identidad cultural y la idiosincrasia de la región (y muy especialmente de la ciudad) de Murcia. Este grupo cultural (integrado por periodistas y profesionales liberales que se ven apoyados por los grandes terratenientes y títulos nobiliarios, establecidos en Madrid) cristalizará definitivamente (aunque antes ya son observables campañas comunes) durante los tristes acontecimientos de la riada de Santa Teresa del año 1879, que provocará la movilización de las élites intelectuales, y hará resonar el nombre de Murcia hasta en la capital del Sena.

Por supuesto, antes de 1879, hay noticia del músico alemán en la ciudad de Murcia. Sin embargo, estas noticias se limitan a dar cuenta de los estrenos en diversas ciudades europeas de obras de Wagner ${ }^{1} \mathrm{o}$ a ofrecer curiosidades sobre las circunstancias que rodean la obra y vida del músico, especialmente en su relación con Luis II $^{2}$; quizás la información más interesante de esta época sea la referida a los conciertos que en los jardines del Retiro de Madrid lleva a cabo Jesús Monasterio como director. Referente a éstos, en 1873, leemos: "respecto a la música de Wagner es al pronto de un efecto casi incomprensible pero de una novedad tan exacta, que suplicamos al director de la orquesta procure repetirla de nuevo", mientras que en 1876, se afirma que "de las obras que formaban el programa se han repetido entre ruidosos

1 Por ejemplo la inauguración del teatro de Mónaco con una obra de Wagner (Cf. La Correspondencia de España, 31 de diciembre de 1865) o las funciones de Lohengrin en Florencia (Cf. La Paz de Murcia, 3 de diciembre de 1871). Mayor atención merecen las actividades desarrolladas en Bayreuth, de las que se da cuenta desde el momento en que se proyecta el "nuevo teatro" (Cf. La Paz de Murcia, 13 de diciembre de 1872) hasta la representación en éste de El oro del Rin, con asistencia de "veinte soberanos", y de la que se destaca "la música de la orquesta invisible, las magníficas decoraciones y la hábil maquinaria, que causaron grande impresión en el público, que aplaudió vivamente" (Cf. La Paz de Murcia, 18 de agosto de 1876). Igualmente, para mostrar la expectación ante la de Sigfrido, La Paz de Murcia informa de la representación de la prensa en Bayreuth: "París ha enviado 48 periodistas; Londres 48, Nueva York 44, Berlín 20, Viena 15, Holanda 2, Italia ninguno", añadiendo que "España no ha enviado, que sepamos, periodistas a Bayreuth, pero deben hallarse allí dos distinguidos maestros españoles" (Cf. La Paz, de Murcia, 20 de agosto de 1876).

2 En 1873, La Paz de Murcia se hace eco de la prohibición por parte de Wagner de la representación de su ópera Tristán e Isolda en Berlín, porque, "según él, no hay en Berlín un director de orquesta capaz de dirigirla" (La Paz de Murcia, 19 de enero de 1873). Igualmente, se da cuenta de las excentricidades de Luis II, como la construcción de una cabaña en su palacio, igual a la del primer acto de Walkiria (Cf. La Paz de Murcia, 4 de mayo de 1877); a propósito del rey, y su candidatura al trono de España en 1870, leemos: "tiene veinticinco años [...] es gran amigo de Wagner, el músico del porvenir, y ha traducido a su idioma algunas comedias y zarzuelas, con lo cual tiene títulos para dirigir un conservatorio, más una nación" (La Paz de Murcia, 2 de septiembre de 1870). 
aplausos la obertura de la ópera Tannhäuser, del maestro Wagner, a pesar de la oposición apasionada que encuentra en una parte del público la música del porvenir"’3.

El 11 de diciembre de 1879, La Paz de Murcia informaba de lo avanzado de la impresión del periódico París-Murcie, en el que habría un estudio sobre la música de Wagner suscrito por Offenbach ${ }^{4}$; por la importancia del París-Murcie en la historia cultural y periodística de la ciudad, podemos considerar la inclusión de este texto como un momento fundacional en el movimiento wagneriano en Murcia (antes de este escrito ya se habían conocido otros, como el ensayo biográfico-crítico de Marsillach, reseñado por Peña y Goñi ${ }^{5}$, o la poesía laudatoria del poeta murciano Antonio Arnao, A Wagner). Por otra parte, éste es el momento en que, aunque aún tímidamente, comienza a escucharse la música de Wagner en Murcia, bien a través de las bandas de música, bien en el espacio reservado a la música doméstica ${ }^{6}$. La prensa continua prestando atención a los estrenos en Europa y España de las óperas wagnerianas: "el acontecimiento del Teatro Real" que supone el estreno de Lohengrin", El "éxito ruidoso" de El Ocaso de los Dioses en Berlín, el odio mutuo entre Wagner y los franceses o las representaciones de Parsifal en Bayreuth, en una crónica en la que progreso musical y progreso tecnológico aparecen unidos mediante la Exposición de Viena: "la Rotonda estará en conexión telefónica con la Ópera y acaso también con Bayreuth, en donde se ejecutará el Parsifal, de tal manera que los visitantes de la Exposición podrán oír la última obra de Wagner desde una distancia de más de cien leguas"8. Junto a estos acontecimientos, es de destacar la entrada de Wagner en 1885 en el Teatro Romea de Murcia, aunque aún dentro del repertorio italiano; en la despedida

3 Cf. La Paz de Murcia, 17 de agosto de 1873 y 7 de marzo de 1876, respectivamente.

4 Las actividades llevadas a cabo en París (especialmente por Edouard Lebey) para socorrer a las víctimas de la riada murciana de 1879 culminaron en una fiesta en el Hipódromo de París (que reflejó notablemente Marcel Proust) y en el periódico benéfico Paris-Murcie, de 24 páginas, con portada de Gustave Doré, y con autógrafos y artículos del Papa León XIII, el Rey de España Alfonso XII, Alejandro Dumas, Víctor Hugo, el Marqués de Molins, Sarah Bernhardt, Offenbach, Daudet, o Zola, entre otros.

5 En varios números de La Paz de Murcia se informa de este texto presente en Crónica de la música. A propósito de Peña y Goñi, La Paz de Murcia publicó un artículo (firmado por M. Perillan) criticando duramente al crítico, que había tildado al piano de instrumento "antipático" y "anti-armonioso"; en el texto, la crítica a Peña y Goñi se deslizaba hacia Wagner: "¡Tormento de la humanidad dice que llama al piano Ricardo Wagner! ¿Conocen ustedes la música del porvenir, de Ricardo Wagner...? Traslado al que la conozca para que se explique el motivo del antagonismo. Creo que ha hecho usted una plancha, Sr. Peña y Goñi, pues maestros más autorizados que Wagner califican al piano de rey de los instrumentos" (Cf. La Paz de Murcia, 4 de abril de 1878).

6 El Diario de Murcia informaba del programa del concierto en la Glorieta de Murcia a cargo de la banda dirigida por D. Ángel Mirete, en el que junto a pasodobles, valses y obras de Meyerbeer, aparecía la "sinfonía de la ópera Rienzi" (Cf. El Diario de Murcia, 12 de septiembre de 1880). Respecto a la ejecución en domicilios particulares, tenemos constancia por el anuncio que dicho periódico hacía del "almacén de pianos, harmoniums y música” del Sr. Gascón en Murcia, en el que además de instrumentos y utensilios varios, se podían adquirir "una gran colección de óperas para piano y canto y piano solo, entre las que se encuentran Aida, Le Roi de la Hore, Tannhäuser, Lohengrin, Romeo y Julieta, Raimond, L'Ombra, La Ebrea, etc." (Cf. El Diario de Murcia, 5 de mayo de 1880).

7 Cf. El Diario de Murcia, 27 de marzo de 1881. La Paz de Murcia, en la misma fecha, publicaba la carta del Sr. Stagno a Rovira expresando su molestia por no haber sido él el encargado de cantar Lohengrin, siendo sustituido, sin causa aparente, por Julián Gayarre (Cf. La Paz de Murcia, 27 de marzo de 1881).

8 Para el éxito de El Ocaso de los Dioses Cf. La Paz de Murcia, 12 de mayo de 1881; para el odio entre Wagner y los franceses, la crónica firmada por Cherubini, aparecida en El Diario de Murcia, 22 de agosto de 1882; para la exposición de Viena Cf. La Paz de Murcia, 28 de marzo de 1883. A propósito de Parsifal, Juan Talero publicaba una reseña sobre los conciertos de los jardines del Buen Retiro de Madrid del año 1882, dirigidos por Fernández Caballero: en ella, cómicamente recomendaba a Wagner, que estaba buscando "efectos desconocidos" para su Parsifal, que escuchara a Julio Ruiz (afamado actor de zarzuelas) cuya "voz no estaba ajustada a ningún diapasón"; más allá de la broma, Talero destacaba la ausencia de Chapí en los conciertos, que lamentaba profundamente, pues éste, "experto músico, sabía escoger con gran cuidado las piezas de concierto. Por él conocimos los Niebelunguen de Wagner" (Cf. El Diario de Murcia, 27 de junio de 1882). 
de la compañía que actuaba en el coliseo, con El Barbero de Sevilla, durante los intermedios se ejecutaron diversas piezas: en el segundo, la orquesta ofreció la sinfonía de Rienzi $i^{9}$.

Durante los años siguientes, se continuará prestando atención a la actividad relacionada con Wagner fuera de la ciudad ${ }^{10}$, pero comenzarán las campañas propagandísticas de la música de Wagner en la prensa de Murcia. Como ya hemos dicho, la asunción de la "música del porvenir" no fue un fenómeno que se desarrollara con naturalidad; en el camino hacia la nueva música hubo fuertes batallas dialécticas, con detractores e impulsores de la música de Wagner, elevando a éste a la categoría de profeta o visionario. Los que en Madrid se llamaron Pardo Bazán, Rubén Darío, Peña y Goñi,... y en Barcelona, Marsillach, Letamendi, Pedrell,... en Murcia tuvieron los nombres de Julián Calvo, Joaquín Payá, y Mariano Padilla ${ }^{11}$.

Julián Calvo es el primero (cronológicamente hablando) en defender la obra wagneriana y, quizá por ello, el que lo hace de manera más tímida. En su crítica de los conciertos del sexteto del maestro Arche, a pesar de no estar incluido Wagner en el programa, aprovecha para (tras enumerar a Weber, Rossini, Berlioz, Mercadante y Meyerbeer) afirmar que "el gran Wagner ha hecho saber que la instrumentación de una ópera puede influir de una manera poderosamente filosófica en la asimilación escénica", al tiempo que proclama el carácter civilizador de la música (idea presente en todos los defensores del arte wagneriano), declarando que al lado de la educación religiosa debe estar la educación musical ${ }^{12}$. Algo más convincente se muestra al reseñar la despedida de la compañía italiana del Teatro Romea, y, especialmente, la interpretación de la sinfonía de Rienzi:

De buen grado escribiríamos algunas páginas sobre la influencia que la música del maestro Wagner viene ejerciendo durante algunos años sobre muchos maestros, y aún en aquellos que, sin querer seguir estas huellas, su imaginación va en pos del camino trazado por tan titánico genio ${ }^{13}$.

9 Rienzi aparece así mezclado con la música italiana (la ópera que se ofrece es El Barbero de Sevilla) y aún con la francesa, pues al finalizar la representación todos los artistas cantan 'La conjura' de Los Hugonotes (Cf. El Diario de Murcia, 4 de junio de 1885). Estamos aún en una época de reticencia y desconfianza hacia la música de Wagner: así, en un artículo (sin firma) publicado en 1882, se alababa el creciente gusto del público hacia la ópera (italiana o francesa), denostando la zarzuela, "género tonto", y añadiendo "Wagner me parece a mí que también tiene algo tonto; pero no lo crean ustedes por mi palabra" (Cf. El Diario de Murcia, 13 de abril de 1882).

10 Especialmente los incidentes relacionados con el estreno de Lohengrin en París y las demostraciones anti-germánicas (Cf. La Paz de Murcia, 27 de abril, 5 y 6 de mayo de 1887), la representación en Bayreuth de Parsifal y Los Maestros Cantores (Cf. La Paz de Murcia, 31 de julio de 1888), el estreno de Lohengrin en Valencia (Cf. La Paz de Murcia, 31 de julio de 1888), los incidentes de 1891 nuevamente en Paris con la representación de Lohengrin (Cf. La Paz de Murcia, 19 de septiembre de 1891), y las representaciones de Tannhäuser (Cf. La Paz de Murcia, 18 de noviembre de 1894), de Lohengrin con "nuestro compatriota señor Viñas" (Cf. El Diario de Murcia, 9 de marzo de 1895) y de El buque fantasma (Cf. El Diario de Murcia, 30 de octubre de 1896) en el Teatro Real de Madrid.

11 La difusión del wagnerismo en España estuvo asociada a las ideas de regeneración y educación del pueblo, especialmente en Barcelona, donde además, se ligó a las aspiraciones del nacionalismo catalán. En este sentido, los promotores del movimiento wagneriano en Murcia se mostraron más realistas, ya que era difícil aspirar a la regeneración de un pueblo por medio de un arte que le estaba vedado, no solo por su contenido intelectual, sino, y muy especialmente, por los precios de las localidades en que éste se ofrecía.

12 Cf. La Paz de Murcia, 2 de mayo de 1883. En este texto, Julián Calvo aprovecha la ocasión para destacar el nombre del compositor murciano Gaspar Espinosa, y para responder a una misiva de su amigo Antonio Ramírez, como veremos, detractor de la música wagneriana. Curiosamente, toda la crítica está dirigida a las lectoras, en femenino.

$13 C f$. La Paz de Murcia, 7 de junio de 1885. A pesar de que la crónica se refiere a la interpretación de El Barbero de Sevilla (y las actuaciones durante el primer y segundo intermedio y fin de fiesta), de los diez párrafos que la componen, cinco están dedicados a la pieza de Wagner, que en la representación ocupa discretamente únicamente el segundo intermedio. 
Mucho más decidido se muestra Joaquín Payá al reseñar los conciertos del año 1891 de la Sociedad de Conciertos en el Teatro Real: "profetizó que su música sería la música del porvenir, y su profecía se ha cumplido" 14 . Para el crítico, los conciertos dirigidos por Mancinelli ("partidario entusiasta de la reforma musical") representan el triunfo definitivo de la nueva música en España, al interpretarse en ellos fragmentos de todas las obras del compositor, y al pedir el público "un concierto todo de Wagner"15. Aprovecha Joaquín Payá los conciertos para mostrar a los murcianos la titánica obra wagneriana: cuatro artículos dedica a esta labor, y aunque denuncia su "falta de conocimientos" y la "falta de espacio" para decir todo lo que quisiera, no deja de hacer una reseña histórica de Wagner, haciendo parada obligada en el fracaso inicial en París. No es la de Payá una crítica musical especializada; apenas habla de la ejecución concreta de los conciertos. Guiado por "ese altruismo artístico que nos obliga a hablar de lo que nos impresiona para que todo el mundo sienta la misma impresión"16, lo que Payá hace es mostrar, describir, ensalzar, "la música del porvenir" ("música genial y a primera vista extraña") ${ }^{17}$ para los murcianos, desconocedores en gran parte de ésta: así, describe la escena final de El fuego encantado de La Walkiria como "un pasaje divino" del que "solo la palabra 'sublime' en su más alta significación puede dar idea de su valor"; de Los murmullos de la selva (pasaje "que crispa y electriza”) afirma que está lleno de "verdad y poesía que encanta"; y señala Los Maestros Cantores de Nüremberg como el Barbero de Wagner, "pero más delicado, más ingenioso y a la vez más profundo"18. Parsifal queda reservado para el último artículo, al que se añade otro firmado por Joaquín Báguena, centrado en la temática del mismo. Báguena, que considera su texto un complemento a la crítica musical de Payá (por ello quizás solo se ocupa del libreto), demuestra conocer los escritos teóricos de Wagner, alaba la elección de la temática caballeresca de sus obras ("una gran música necesitada de un gran asunto") y, al centrarse en Parsifal, relata la que cree leyenda original, indicando las transformaciones realizadas por Wagner: "no es el Parsifal de Wagner una sencilla fábula; hay un profundo y moralizador simbolismo en cada una de aquellas figuras"19.

Si Julián Calvo había sido relativamente tímido, y Payá y Báguena habían relatado con entusiasmo los conciertos en el Teatro Real, la pasión por la difusión de la obra wagneriana en Murcia tendrá un nombre propio: el del tenor Mariano Padilla quien, entre 1895 y 1899, propagará en sus cartas desde

14 Cf. El Diario de Murcia, 12 de marzo de 1891

15 Loc. Cit.

16 Cf. El Diario de Murcia, 17 de marzo de 1891

17 Loc. Cit.

18 Cf. El Diario de Murcia, 28 de marzo de 1891. En esta crónica Payá considera El anillo del Nibelungo una trilogía y no tetralogía (pues, para él, El oro del Rin es meramente prólogo); igualmente, informa que el fragmento de La Walkiria no se tocó tres veces sino seis, ya que tuvo que repetirse en todas las ocasiones. Respecto a la caracterización de Los Maestros como el Barbero de Wagner, añade: "la risa estrepitosa con que ríe la música del Barbero es la de un bufón; la sonrisa retozona de la música de Los Maestros es la de un dios que se burla".

19 Cf. El Diario de Murcia, 1 de abril de 1891. No solo El Diario de Murcia dedicó espacio a los conciertos en el Teatro Real dirigidos por Mancinelli; interesante resulta la crónica firmada por Juan del Real, al hablar en su texto de la suite Peer Gynt (colocando a Ibsen y Wagner a la par), de Liszt, y finalizando por esperar una obra de Chapí en los conciertos (Cf. La Paz de Murcia, 20 de enero de 1891); igualmente descriptiva es la narración de la audición de Parsifal, "la obra de un coloso", escuchada "con religioso silencio", que sirve para disipar cualquier duda sobre el triunfo de Wagner: "los que motejan al gran compositor de oscuro y laberíntico deben oír esta portentosa página de inspiración, que será mientras haya arte y artistas en el mundo, modelo acabado de inspiración mística y poética" (Cf. La Paz de Murcia, 3 de marzo de 1891). 
Baden-Baden y desde Biarritz su devoción por la obra de Wagner y su amor por el pueblo alemán. Los textos de Padilla son quizá los más interesantes que encontramos en la prensa murciana sobre la música del alemán; lejos del esnobismo cultural, Padilla cree fielmente en la obra wagneriana, confundiéndose en sus afirmaciones todas las ideas que predominan en la filosofía y la estética europeas de la época. Como decimos, dos son los ejes sobre los que se asienta el pensamiento del cantante: la germanofilia y la obra wagneriana. Respecto a la primera, el cantante es decidido desde el primer momento: “¡Esa Atenas moderna, esa Walhalla de la inteligencia y de la ciencia, esa Meca artística,... la ciudad de Munich!"20. Mariano Padilla, a diferencia de los autores que hemos visto, viaja y tiene ocasión de conocer de primera mano los lugares a los que se refiere. Queda impresionado por los teatros de Alemania, con Bayreuth a la cabeza, dando las cifras de capacidad de éstos ${ }^{21}$; pero más entusiasmado aún se muestra por la educación musical de los alemanes, en su artículo "La música en las universidades de Alemania":

Alemania cuenta al presente con veinte universidades; diez y seis de ellas inscriben en sus programas de estudio la enseñanza de la música. Yo espero de mis queridos compatriotas que me den una idea aproximada de si se practican en nuestro noble país, como nos llaman después de nuestra desgraciada guerra, iguales procedimientos $[\ldots]^{22}$,

añadiendo que "el diletantismo musical no existe en Alemania; la música constituye una función vital de la Sociedad"23. De este modo, anima a los murcianos a crear una Academia Musical a imitación de la de Munich, en el año 189924. Destacamos la fecha porque no deja de estar presente en Padilla (aunque no de un modo específico) la idea de la decadencia de las razas meridionales frente a los pueblos del Norte, especialmente la raza aria, idea tan del gusto de la época, sobre todo a partir de la derrota del Sedán y del desastre del 98. Otras ideas se desprenden de sus cartas, en las que habla de la prohibición de corridas de toros en Francia, de los contratos de compañías ferroviarias en España, de la guerra y sus consecuencias,... pero sobre todo habla de música, y casi exclusivamente de Wagner; biografiando al autor, confrontándolo a la italianitis imperante en la época, calificándolo como coloso y revolucionario... más adelante, desarrollando un tono más personal e íntimo (que recuerda a otro wagneriano insigne, Luis Millet), al describir la villa de Wagner en Bayreuth ${ }^{25}$. Padilla se aproxima también a los postulados naturalistas, al pretender identificar el carácter de las composiciones con la climatología ${ }^{26}$; en su incesante labor, desarrolla igualmente una crítica detallada del texto La música del porvenir ${ }^{27}$. Pero, sin duda, lo que convierte a Padilla en testigo de excepción frente al resto de críticos, es el vivir los acontecimientos en primera persona, en el lugar donde se desarrollan, convirtiéndose en uno más de los "peregrinos" que acuden a Bayreuth en busca de experiencias místicas:

\footnotetext{
20 Cf. El Diario de Murcia, 10 de septiembre de 1895.

21 Cf. El Diario de Murcia, 1 de septiembre de 1898

22 Cf. El Diario de Murcia, 14 de septiembre de 1898

23 Loc. Cit.

24 Cf. El Diario de Murcia, 26 de agosto de 1899

25 Cf. El Diario de Murcia, 30 de agosto de 1896

26 Cf. El Diario de Murcia, 20 de septiembre de 1896

27 Cf. El Diario de Murcia, 27 de septiembre de 1896
} 
Bayreuth: templo infalible, extraordinario, donde los admiradores de su talento, deberían reunirse todos los años en una peregrinación universal y cosmopolita, con la misión sumisa de testimoniar a su gran profeta sus entusiasmos fervientes ${ }^{28}$.

La pasión por la obra wagneriana no exime al autor de reseñar algunos acontecimientos con relativa objetividad; así, denunciará la baja calidad de la dirección orquestal del hijo de Wagner en 189929. Igualmente, alabará la obra de Donizetti y otros autores franceses e italianos ${ }^{30}$, y buscará, como tantos otros en la época, la regeneración de la escena española mediante la historia y leyendas del propio país ${ }^{31}$.

Hemos destacado los tres autores que con más entusiasmo propagaron la obra wagneriana en Murcia; pero también hubo voces contrarias a la música del porvenir. Una de las más autorizadas y presentes en la prensa es la del profesor y crítico Antonio Ramírez Pagán. En su texto La música en el templo ${ }^{32}$, realiza una defensa de las obras polifónicas de Morales, Victoria y Guerrero, y alaba las creaciones de Verdi y Wagner, no sin aclarar que éstas están sujetas a la ley del tiempo (la moda) y por tanto, pasarán. En 1888, aprovechando la representación de La Bruja de Chapî́33, señala que a pesar de lo dicho por Wagner, aún no se ha alcanzado "la música del porvenir" y en 1890, de modo manifiesto, expresará, en ocasión de la representación de Lucia di Lamermoor en el Teatro Romea, su posición contraria a la nueva música:

Los wagneristas dicen que el porvenir es suyo. Los antiwagneristas... del porvenir no dicen nada, tienen su corazón vuelto al pasado y adoran a Donizetti y Bellini [...] ¿Quiere decir todo esto que yo soy reaccionario en música? Precisamente. [...] Y si no, decidme, ¿hay algún maestro en el mundo, hoy día, que pueda hacer una obra como Lucia di Lamermoor? ${ }^{34}$

28 Cf. El Diario de Murcia, 10 de septiembre de 1895. Igualmente, en 1899 al hablar de las representaciones en Bayreuth de El anillo del Nibelungo dirigido por Sigfried Wagner, aclarará que "en los alrededores del teatro no se oye hablar el alemán porque los que visitan Bayreuth se componen generalmente de gentes que pertenecen a todas las naciones", destacando la presencia de ingleses, seguidos de americanos y belgas, y señalando la escasa afluencia de franceses (Cf. El Diario de Murcia, 26 de agosto de 1899).

29 Cf. El Diario de Murcia, 20 de septiembre de 1899. La cuestión resurgirá en 1907 cuando el hijo de Wagner origine un "gran fracaso" en el Liceo de Barcelona: "el hijo carece de afinidad artística con su padre. Los números de música melódicos sin originalidad, son bastante vulgares. Como director dejó mucho que desear, limitándose a llevar el compás" (Cf. El Liberal, 26 de febrero de 1907).

30 "Yo cada día me voy convenciendo más de que la bella música que pasó, será la verdadera música del porvenir" ( $C f$. El Diario de Murcia, 18 de agosto de 1899). A pesar de ello, seguirá manteniendo que Haydn, Beethoven y Wagner son los genios sinfónicos, mostrando una clara predilección por la música alemana.

31 Cf. El Diario de Murcia, 30 de agosto de 1896. Ésta fue la principal enseñanza de Wagner a sus contemporáneos; aún los contrarios a la "nueva música" manifestaron la necesidad de buscar en la propia tradición los asuntos y temas propicios para salvar la tan traída y llevada decadencia de la escena.

32 Vid. El Diario de Murcia, 30 de marzo de 1887

33 La opinión de Ramírez frente a la obra de Chapí trata de ser objetiva, aunque pronto comprendemos que no es de su agrado. Comienza refiriéndose a la reacción del público: "para unos la obra era admirable y bella, para otros confusa y desigual, para algunos fastidiosa y pesada"; más tarde, se pregunta qué significa La Bruja dentro del campo de la zarzuela: "es un progreso inmenso y a la vez una perturbación. Es un progreso porque el maestro que ha escrito tal partitura es un sabio [...]" (Cf. El Diario de Murcia, 14 de febrero de 1888).

34 Cf. El Diario de Murcia, 13 de mayo de 1890. En el mismo texto podemos leer al confrontar a Wagner y Donizetti: “ Para mí, Wagner es un sabio, un filósofo, un genio, pero un hombre al fin; mientras que Donizetti es un ángel, un iluminado, un hijo del cielo, cuyo lenguaje transmite por medio del pentagrama. Wagner es complicado, científico, matemático. Donizetti es sencillo, inspirado, todo corazón y sentimiento. Wagner es la razón, la lógica y la ciencia invadiendo y ocupando por conquista el terreno 
Aún dentro de la misma temporada, al representarse Hernani y Fausto ${ }^{35}$, vuelve a tildar la música wagneriana como difícil y dura, música para analizar y no para disfrutar, crítica en la que coincidirá con otro intelectual contrario a la música de Wagner, Andrés Blanco.

No se prodigó excesivamente en asuntos musicales Andrés Blanco, pero aprovechó las oportunidades que se le presentaron para atacar la nueva concepción musical. Así, el 16 de febrero de 1888, publica una respuesta al artículo de Antonio Ramírez sobre La Bruja de Chapí: “yo también voy a emitir mi opinión, humilde, humildísima como mía, más que sobre la magistral obra de Chapí, sobre el giro que va tomando la música en los tiempos actuales"36. Denuncia Andrés Blanco lo complejo de la nueva música, apta para los alemanes, pero no para el pueblo español, "menos pensador que el alemán, pero más dado a las exaltaciones de la fantasía, que necesita otra música distinta a la fría y monótona de los hijos de allende el Rin" 37 , subrayando que:

Producir música para los inteligentes nada más, es peor que no escribirla para nadie. Escribir música que no llegue al corazón y a la inteligencia de los profanos con esa espontaneidad con que llegan la poesía, la pintura o la escultura, no es realizar la belleza por completo, sino cercenarla con avaricia ${ }^{38}$.

del arte"; y más adelante: "el que en la actualidad dirija una mirada al mundo musical moderno advertirá enseguida la crisis por que está atravesando. Las teorías y procedimientos wagnerianos han invadido todos los conservatorios del mundo. Y al mismo tiempo la esterilidad artística es tal que no hay obra nueva, desde hace mucho tiempo, con que pueda contarse para agregarla al gran repertorio universal, y a todo el antiguo".

35 "¿Qué me importa a mí que exista Wagner y su escuela si ésta se ha subido a un séptimo cielo!, tan distante de este mundo que nos hemos de quedar sin oírle ni entenderle la inmensa mayoría de los mortales. Reniego del progreso musical que ha hecho imposible nuevas Lucias y nuevos Trovadores. Todo quiero concedérselo a los wagnerianos, menos que esos músicos italianos a quienes tanto desprecian, han conmovido con sus melodías insuperables el mundo entero [...] Mientras yo vea y sepa que hay personas, y muchas, capaces de analizar, técnicamente cualquier obra wagneriana, y sin embargo, salen después de oírlas ejecutar como el negro del sermón, tengo el derecho de dudar de que lo presente sea, en absoluto, superior al pasado". Cf. El Diario de Murcia, 20 de mayo de 1890.

36 Cf. El Diario de Murcia, 16 de febrero de 1888. El que los críticos traigan a colación a Wagner a propósito de Chapí no es algo extraño en la época ni en la prensa murciana; así, en 1890, encontramos la censura de Salvador Canals al compositor de Villena por su (en palabras del crítico) "bufonada indecorosa" Para hombres solos, presentada en el Teatro Eslava: "Chapí en Eslava, ha escrito Mariano de Cavia para decir lo mismo, Chapí se degrada, como se degradaría Pérez Galdós si se pusiera a escribir novelitas para el Demi-Monde [...] ¡Mire Vd. que haber ido este verano a Bayreuth a empaparse de las místicas sublimidades de Parsifal y del encantador simbolismo de Los maestros cantores de Nuremberg, para exponerse ahora, en Eslava, al fracaso de la obrita intitulada Para hombres solos!... Y es que Chapí se ha metido a limosnero del arte, y le da notas al primer Arniches que se las pide" (Cf. La Paz de Murcia, 16 de diciembre de 1890).

37 Cf. El Diario de Murcia, 16 de febrero de 1888.

38 Loc. Cit. Continua Blanco su argumentación alabando a Meyerbeer, "el genio que más comprendió el arte y que mejor interpretó la escena", en contra de "la manera de Ricardo Wagner, árida, seca, académica": "De continuar las exageraciones ya iniciadas, día llegará en que una obra teatral sea un conjunto de insoportables recitados embutidos en una orquestación riquísima en acordes y giros no oídos, pero más pesados y soñolientos que los de las exageraciones melódicas". Todo ello sirve al crítico para censurar a Chapí, al que acusa de haber abandonado la que él llama "escuela melódica" (representada por obras como La Favorita o Norma) y afirmando que "extranjerismos" como el de Chapí en La Bruja, o "las frivolidades e insulseces de las Grandes Vías" apartan a los músicos del camino hacia la ópera nacional. Aún insistirá en esta idea en su artículo dedicado al nuevo Miserere ejecutado en la Catedral de Murcia: "mientras la música teatral sigue una marcha vacilante en pos de un ideal que no encuentra, y la ópera se empobrece entre los extranjeros, y la zarzuela seria se relega entre nosotros casi al desprecio para dar paso a esas ligeras vestiduras musicales con que se encubren tantos disparates y desvergüenzas literarias [...]" (Cf. El Diario de Murcia, 17 de abril de 1892). En dicho artículo, alababa la labor de Juan Pelegrin, autor del Miserere, por haber sabido "vencer los escollos de la aridez en que tropiezan los que intentan seguir la escuela de Wagner". Encontraremos ideas muy similares en los tres artículos publicados por el autor en la revista Cartagena Artística bajo el título "La música del porvenir", en el que resume el arte musical del XIX en las presencias de Rossini y Bellini (que a finales de siglo resultan algo "pueriles e ingenuos"), el ataque a Boito y Wagner, y la alabanza a Meyerbeer, Gounod, Verdi (tras Aida) y, por supuesto, Donizetti, para el crítico el mejor compositor del siglo: "el deseo 
Otros muchos fueron los textos de uno y otro bando que se insertaron en la prensa para defender las respectivas posiciones, llegando a citarse y copiarse parte de las conferencias de Felip Pedrell en Madrid $^{39}$. Pese a todo el debate, y auspiciado por los partidarios de la nueva música, el movimiento wagneriano va ganando las primeras batallas fuera de la prensa, esto es, en el terreno de la audición. Además de la actividad de las bandas ${ }^{40}$ y la música doméstica, otras instituciones de la ciudad comienzan a implicarse en la difusión de la música de Wagner: así, el Círculo Católico, donde los murcianos tienen ocasión de escuchar, junto a piezas de Saint-Saëns, Liszt, Thomas, Rossini o Meyerbeer, la romanza de Tannhäuser al armonio ${ }^{41}$. No obstante, faltaba el asalto definitivo al Teatro Romea; en 1895, dos acontecimientos propician la entrada de Wagner en el murciano coliseo: por un lado, la actuación en éste de Mila Kupfer (pues aprovechando ésta, se publica su biografía en El Diario citando en repetidas ocasiones a Wagner), y por otro, el concierto vocal e instrumental a cargo de "la eminente diva Sra. Emma Nevada" con participación del tenor Gomis; en éste, mientras la diva se reserva las piezas de lucimiento del repertorio francés (vals de la sombra de Dinorah de Meyerbeer o vals de Romeo y Julieta de Gounod), el tenor Gomis interpreta el raconto de Lohengrin ${ }^{42}$. Cuatro años más tarde se producirá la representación completa de esta ópera.

\section{EL ESTRENO DE LOHENGRIN EN MURCIA (1899)}

Denominar acontecimiento musical a lo sucedido en Murcia en el año 1899 no es exageración a juzgar por los esfuerzos por atraer una compañía de ópera "tan excelente como pocas veces se habrá logrado en provincias" ${ }^{43}$. Dicha compañía ofrecería ocho funciones en abril (del 11 al 18), con los títulos

de avanzar rápidamente en la escala del progreso nos ha llevado desde Rossini hasta Wagner, es decir, desde la sencillez suma pero clara y espontánea hasta la complicación nebulosa, convirtiendo la belleza en un jeroglífico" (Cf. Cartagena Artística, n ${ }^{\circ} 22,24$ y 26, noviembre-diciembre 1890).

39 A modo de ejemplo, en 1886 encontramos en La Paz de Murcia una reseña crítica del libro de Adolfo Julien, Ricardo Wagner, su vida y sus obras (Cf. La Paz de Murcia, 14 de agosto de 1886); en 1892, al criticar duramente las modas, se apunta cómo "los profanos no se explican por qué está de moda la música de Wagner sobre la italiana, y el naturalismo sobre el romanticismo, y el positivismo sobre el espiritualismo, y otros muchos ismos" (CF. El Diario de Murcia, 21 de febrero de 1892). Eduardo Bermúdez, como corresponsal en Madrid de El Diario, al reseñar el triunfo de Ensayo general de Celso Lucio y Fernández Caballero, destacaba "un trozo de música descriptiva, en el que el insigne maestro imita con mucha gracia el modo de hacer de Wagner" (Cf. El Diario de Murcia, 1 de marzo de 1896). A propósito de las conferencias en Madrid de Pedrell, podemos leer: "siguiendo las doctrinas establecidas por Wagner, como fundamento de la estética musical, opina el señor Pedrell, en la canción popular han de buscarse el fundamento y origen del drama lírico" (Cf. El Diario de Murcia, 13 de febrero de 1896).

40 Es interesante notar la coincidencia en los programas de éstas de los nombres asociados a Wagner: así, en 1891 encontramos en el concierto de la Banda de la Misericordia en la Plaza de Jofré de Murcia, la marcha de Tannhäuser junto a los cuatro tiempos de La corte de Granada de Chapí (Cf. El Diario de Murcia, 13 de septiembre de 1891)

41 Cf. El Diario de Murcia, 12 de febrero de 1893. El encargado de ejecutarla es Antonio Puig, que ya había tenido ocasión de hacerlo en una velada musical organizada en casa de Francisco Puig (su padre), donde tocó dicha romanza en el armonio de López Almagro, y algunas danzas húngaras de Brahms, así como piezas de Schumann (Cf. El Diario de Murcia, 19 de enero de 1893). Es interesante destacar los músicos participantes en esta velada del Círculo Católico pues, posteriormente, serán los grandes difusores de la obra wagneriana en Murcia: Puig, Martí, Puche, Sanz, y Noguera, entre otros.

42 Cf. El Diario de Murcia, 15 de mayo de 1895. El resto del programa quedaba integrado por un zortzico, una canción rusa y una romanza de Tosti, además de sinfonías ejecutadas por la orquesta.

43 La compañía estaba integrada por tiple dramática (Rosa Caligari), tiple ligera (Dolores D’Arroyo), tiple contralto (Fidela Gardetta), tiple comprimaria (Argelina Pelayo), tenor dramático (Franco Cardinalli), tenor ligero (Manuel Maestre de San Juan), tenor (José Tanci), barítonos (Alejandro Arcangeli y Guillermo Romero), bajos (Salvador León y Manuel Candela), treinta 
Otello, Gioconda, Aida, Africana, Rigoletto, Favorita, Sonámbula y, "para aquellos deseosos de conocer los progresos del arte en obras modernistas", Lohengrin. Gran expectación hubo ante este último título, cuyo estreno se verificó el 25 de abril, apareciendo el mismo día por la mañana en portada y a cuatro columnas, una reseña sobre la ópera firmada por Antonio Ramírez, opuesto a las teorías wagnerianas, como hemos visto.

Indica Ramírez en este texto la necesidad de dar algunas pinceladas sobre "tan controvertido" músico a sus lectores, en ocasión de tal estreno. En ellas, no duda en afirmar que aquel porvenir del que hablaba Wagner, "es ya el presente: Wagner ha vencido de hecho. No solo todos los grandes teatros, sino también todos los grandes centros docentes del mundo, han aceptado sus obras y sus teorías"44. Tras la concesión, rápidamente se pregunta: “QQuiere esto decir que la victoria es completa? [...] De ninguna manera”, y de este modo, retomando el clásico debate sobre la primacía del texto o de la música en los espectáculos líricos, plasma sus ideas sobre la dificultad de la obra wagneriana, obra matemática, difícil, no apta para el deleite: "Los que saben Wagner a disfrutarlo. Dichosos ellos. Los que no lo saben, a estudiar ${ }^{45}$ “. Sin embargo, Ramírez considera Lohengrin fuera de este grupo: "Ahora bien, de las Walkirias a Lohengrin es una cosa así como del Profeta a la Sonámbula. Precisamente por su belleza melódica el Lohengrin ha conseguido agradar a todos los públicos" 46 .

Lohengrin se cantó (en italiano) esa misma noche con el teatro lleno. El público hizo gala de su impaciencia y sus exquisitos modales desde el principio, cuando al salir "un pobre señor a aplacar al pueblo soberano, la pita fue fenomenal" ${ }^{47}$. Por las crónicas, la representación fue de alta calidad, destacando los solistas, la decoración y, muy especialmente, el coro; de la orquesta se señalaban algunos fallos. Wagner gusta, y gana una batalla difícil, la que Antonio Ramírez había establecido con el arte de Bayreuth:

El preludio de la ópera, preciosísima joya instrumental, fue ejecutado por la orquesta a la perfección y muy aplaudido [...] El acto tercero es el mejor. No parece ópera italiana porque no es posible. Pero es la música de Wagner cuando Wagner se humaniza [...] En el acto cuarto está el célebre raconto cuya base orquestal es todo el hermoso preludio del acto primero. La voz canta en libertad completa, y la orquesta, que por sí sola tiene un interés extraordinario, presta a la relación de Lohengrin un encanto sublime. Esto es wagnerismo. Pero es un wagnerismo que entendemos todos ${ }^{48}$.

coristas del Teatro Real, nueve bailarinas del mismo teatro, orquesta de cincuenta profesores del Teatre del Liceu más otros tantos murcianos, decorados a estrenar, así como atrezzo y sastrería. Como directores figuraban Vicente Petri y José Loriente. Cf. El Diario de Murcia, 9 de marzo de 1899

44 Cf. El Diario de Murcia, 25 de abril de 1899

45 Loc. Cit. En el mismo artículo, hablando del público: "un público que oye a Wagner se divide en tres categorías: los que lo entienden, que son muy pocos; los que dicen que lo entienden que son más y que pueden, aunque se engañen, decirlo de buena fe; y los que se aburren porque no entienden una palabra".

46 Loc. Cit. Acababa Ramírez animando a los murcianos a acudir al teatro: "tal es el argumento de la ópera de esta noche; ópera que es un milagro que podamos oír en Murcia; ópera que tiene una importancia excepcional y que ningún aficionado a la música debe dejar de ver, siquiera porque es muy difícil, tal vez imposible, que, a lo menos en mucho tiempo, se vuelva a representar". 47 Cf. El Diario de Murcia, 27 de abril de 1899. La entrada general para asistir a esta representación fue de 1'50 ptas., y la hora de comienzo, tal como aparecía en prensa los días anteriores, las nueve en punto.

48 Loc. Cit. 
A pesar de su convencimiento, Ramírez reconoce que la obra no despertó el entusiasmo que las anteriores en el público, atribuyéndolo a dos razones: por un lado, que la obra era desconocida, por otro, algunos acordes excesivamente disonantes y algunas dificultades de la orquesta ${ }^{49}$. También parece agradar a Andrés Blanco el Lohengrin, realizando algunas concesiones a la música de Wagner ${ }^{50}$, aunque reafirmando las críticas realizadas con anterioridad. Este texto (que Blanco dirige a Ramírez), provoca la aparición de otro, firmado por Mariano Marín (a quien vimos interpretando a Wagner en las veladas del Círculo Católico) y dirigido "a los Sres. D. Antonio Ramírez y D. Andrés Blanco”. Aún afirmando desde un principio no buscar una polémica, Marín acusa al "veterano profesor de música” y al "distinguido literato" de falsear la realidad con sus juicios, añadiendo que tales podrían ser propios de aficionados, pero no "de los que saben o deben saber":

Tanto el Sr. Ramírez como el Sr. Blanco acusan a Wagner de oscuro e ininteligible, que su música sea algo así como un jeroglífico cuya solución pueden solamente encontrar aquellos pocos que han encanecido en el estudio del tecnicismo del arte, y esto es sencillamente una exageración, o mejor aún, es un atrevimiento asaz temerario el juzgar así de plano, a la primera y bastante mediana audición una obra tan colosal ${ }^{51}$.

Continúa detallando su argumentación Mariano Marín, corrigiendo a Ramírez en la cuestión de los acordes disonantes de Lohengrin: "varios instrumentos de la orquesta, como los trombones, bass-tuba y el importantísimo oboe estaban desafinados, y de aquí esos acordes muy disonantes que dice el Sr. Ramírez" ${ }^{2}$, para acabar colocando a Wagner como "el genio que después de Beethoven ha elevado la música al más alto grado de perfección, y dado excepcional importancia al drama lírico" ${ }^{53}$. El texto tiene respuesta velada por parte de Andrés Blanco, quien escribe otro (nuevamente dirigido a Antonio Ramírez), donde concede cierto beneplácito a algunas obras de Wagner ${ }^{54}$, y que finaliza dando las gracias "al fervoroso wagnerista Mariano Marín, por haberme dedicado parte de un artículo en donde, sin pruebas, sostiene una opinión contraria a la humilde mía. Y basta ya de Wagner" ${ }^{55}$. No responde Antonio Ramírez (el tercer implicado) a Andrés Blanco, o sí; durante el verano de 1900, una compañía de ópera italiana actúa en el Teatro Circo Villar (rival del Romea), ofreciendo Aida, Cavalleria Rusticana, I Pagliacci, Los Hugonotes, Lucia, Mefistófeles, Rigoletto, La Favorita, Sansón y Dalila, Fausto, Hernani, La Bohème y Lohengrin. Al realizar la crítica de la temporada, Ramírez alaba enormemente Cavalleria Rusticana, pone

49 Loc. Cit.

50 "En Wagner todo es personal, todo es debido a su profundísimo talento y no puede formar escuela [...] Wagner, a mi juicio, es el que mejor ha entendido el drama lírico teatral" Cf. El Diario de Murcia, 29 de abril de 1899.

51 Cf. El Diario de Murcia, 2 de mayo de 1899

52 Loc. Cit.

53 Loc. Cit.

54 "Hay momentos en que dejándose Wagner llevar de la inspiración, brotan de su pluma melodías tan bellas como sentidas [...] eso acontece en Tannhäuser, Parsifal y Lohengrin, que son precisamente donde Wagner respeta, todavía a ratos, el encanto melódico y la regularidad de la frase. No así, me aseguran, en las obras posteriores" Cf. El Diario de Murcia, 4 de mayo de 1899 55 Loc. Cit. 
por delante el Fausto de Gounod al Mefistófeles de Boito, y al comentar La Bohème (especialmente el primer acto) critica el burdo asunto de ésta: "en esto Wagner tiene razón. Para los dramas líricos, cuanto más lejos mejor. Wagner llega hasta el mito"s6.

\section{LA LABOR DE MARTÍ, PUIG Y LOS CONJUNTOS DE CÁMARA (1899-1909)}

A pesar del notable triunfo que significa la representación de Lohengrin en el Teatro Romea, no supone el estreno del resto de obras wagnerianas. Lohengrin volverá a representarse dentro de las breves temporadas de ópera que los teatros Romea y Circo Villar llevarán a cabo, pero la difusión del resto de la producción de Wagner se realizará por otra vía, esto es, por medio de los conjuntos de cámara.

La actividad de los conjuntos de cámara de la ciudad surge a partir de los esfuerzos individuales de una serie de músicos de los que ya hemos hablado. Agrupados en quintetos o sextetos, su repertorio va a ser variado, al igual que los lugares donde actúen; sin embargo, existe una unidad derivada de sus integrantes: Enrique Martí y Antonio Puig, que aparecen como aglutinantes del grupo, formado además por Marín, Puche, Sanz, Espada, Jover, Rizo y Gamuz, según el concierto. Aunque decimos que fueron varios los lugares donde actuaron, podemos agrupar su actividad en torno a dos núcleos: por una parte, los conciertos dados en cafés y hoteles; por otro, las actividades relacionadas con el Círculo de Bellas Artes de Murcia.

Durante las primeras décadas del siglo xx, la música en los hoteles y cafés de Murcia tuvo un protagonismo destacado. Lejos de ser un mero solaz, la prensa daba cuenta de la hora y programa de los conciertos que se llevaban a cabo en estos establecimientos ${ }^{57}$, siendo los lugares predilectos para la ejecución de estos recitales los cafés del Arenal y Moderno, y los hoteles Patrón y Palacio Hotel. En ellos actuaba el sexteto de Antonio Puig, y su repertorio incluía obras de compositores nacionales (Tomás Bretón, Fernández Caballero, Chapí,...) e internacionales del gusto del público (Strauss, Verdi, Puccini,...), encontrando en casi todos los conciertos alguna pieza de Wagner (de éstas, las obras más tocadas eran la marcha de Tannhäuser y una fantasía sobre Lohengrin) ${ }^{58}$. La presencia de Wagner en los conciertos venía justificada, sin duda, por los "jóvenes maestros" que integraban los sextetos: baste recordar que Antonio Puig había interpretado desde muy joven Tannhäuser, Marín se había manifestado como entusiasta wagnerista en el estreno de Lohengrin y Martí igualmente se había acreditado como ferviente admirador

56 Cf. El Diario de Murcia, 5 de octubre de 1900

57 Aunque queda fuera de las pretensiones de este artículo, podemos consignar que esta actividad fue igualmente importante en Cartagena, en locales como el Café del Arenal o el Café de España; en éste último, sabemos que existió un sexteto que tocaba lunes y jueves obras de Grieg, Massenet, Wagner, Meyerbeer y otros (Cf. El Liberal, 19 de febrero de 1903)

58 Los programas de estos conciertos denotan su carácter popular dada su falta de unidad y heterogeneidad en estilos y autores; baste destacar el programa del concierto ofrecido en el Palacio Hotel el 14 de septiembre de 1911, donde las cinco piezas son la marcha de Tannhäuser, En la alhambra de Bretón, fantasía sobre Aida, fantasía sobre La Marsellesa de Fernández Caballero y Los encantos de un vals de Strauss (Cf. El Liberal, 14 de septiembre de 1911); igualmente, el ofrecido el 29 del mismo mes y año: Marcha rusa de Ganne, final del acto $3^{\circ}$ de La Bohème, Canción de Solveig de Grieg, fantasía sobre La Verbena de la Paloma y marcha de Tannhäuser (Cf. El Liberal, 29 de septiembre de 1911). En ocasiones Wagner era interpretado junto a fragmentos de zarzuelas como El barberillo de Lavapiés, de operetas españolas como Molinos de Viento, u operetas vienesas como La princesa del Dollar o Eva. 
del músico alemán. De este modo se explica el programa "extraordinario" que Enrique Martí y Roberto Cortés, convertidos en dúo, ofrecieron en el Hotel Patrón el 23 de septiembre de 1911: Canto de amor de La Walkiria, Fantasía de Lohengrin, Fantasía de Los Maestros Cantores, Fantasía del Buque Fantasma, Fantasía de Tannhäuser y Marcha de Rienzi $i^{59}$.

Junto a la actividad en hoteles y cafés, es de reseñar toda la vida musical auspiciada por el Círculo de Bellas Artes de Murcia ${ }^{60}$. El Círculo de Bellas Artes fue un auténtico dinamizador cultural de la ciudad: organizó veladas literarias y musicales, fomentó y ayudó en sus estudios a los posibles artistas sin recursos económicos, y colaboró en todos los actos benéficos y culturales de la ciudad. El 25 de enero de 1903 ya observamos un concierto organizado por una pequeña orquesta (seis músicos) en esta institución; en él vemos reunidos a Antonio Puig y Enrique Martí, en un programa que integra una fantasía sobre Lohengrin, la danza del templo (para piano) de Grieg, el vals de Fausto de Gounod, un bailable de Gioconda de Ponchielli y una fantasía sobre La Bohème ${ }^{61}$. Igualmente, en septiembre del mismo año el Círculo organiza en el Teatro Circo Villar un "Festival artístico" con un extenso programa, en el que figuran la obertura de Rienzi (primera pieza del programa) y el coro de peregrinos de Tannhäuser, interpretado por el Orfeón de Alicante, invitado a la ciudad por la institución ${ }^{62}$. Estas veladas literarias van a ir tomando cuerpo e institucionalizándose, especialmente a partir de 1906, donde aparecen con relativa frecuencia los "Conciertos matinales" a cargo del sexteto, con gran éxito de público: entre las obras, encontramos nuevamente una amplia gama de estilos, con obras de Schubert, Schumann, Liszt, Mendelssohn, Saint-Saëns, Chopin, Beethoven,... de las de Wagner, vuelven a ser protagonistas la marcha de Tannhäuser y la obertura o marcha de Rienzi.

La implantación de los "Conciertos matinales" dará lugar al nacimiento, en el seno del Círculo de Bellas Artes, de la "Sociedad Murciana de Conciertos Clásicos". El primer concierto que consignamos de esta sociedad (que no es más que el sexteto ya aludido) corresponde al día 21 de mayo de 1908, teniendo lugar el evento en el Teatro Romea, con un programa dividido en dos partes: en la primera, obras de Haydn, Mozart y Svendsen; en la segunda, obras de Schubert, Beethoven y, como final, la Marcha de Tannhäuser ${ }^{63}$.En el segundo concierto (una semana después, el día 29) volvemos a encontrar un programa dividido en dos partes (primera con obras de Mendelssohn, Schubert o Mozart, segunda con obras de Grieg y Beethoven), acabando nuevamente con la Marcha, en este caso de Rienzi ${ }^{64}$. Tal es el éxito de esta asociación, que llega a ejecutar en su primer año su quinto concierto, el 27 de noviembre, dedicado íntegramente a Beethoven ${ }^{65}$.

59 Cf. El Liberal, 23 de septiembre de 1911

60 Aunque el Círculo de Bellas Artes fue el principal impulsor de la música en esta etapa, otras instituciones de la ciudad dieron cabida a interpretaciones musicales; curiosa es la velada religiosa del Círculo Católico en 1902, donde junto a las Siete palabras de Haydn, se ejecuta una "brillante fantasía sobre La Walkiria interpretada por el joven y reputado profesor Sr. Martí" Cf. El Diario de Murcia, 13 de marzo de 1902

61 Cf. El Liberal, 25 de enero de 1903. Añadía la breve reseña que en los intermedios de los fragmentos musicales se daría lectura a diversas poesías de socios del Círculo.

62 Cf. El Liberal, 7 de septiembre de 1903

63 Cf. El Liberal, 21 de mayo de 1908

64 Cf. El Liberal, 29 de mayo de 1908

65 Cf. El Liberal, 27 de noviembre de 1908 
El segundo año de actividad de esta agrupación de cámara es saludado efusivamente por Martínez Tornel desde El Liberal:

Los conciertos que este año va a dar el referido sexteto pueden llamarse 'segundo curso de propaganda artística y de alta educación musical', porque en ellos se va a llegar hasta Wagner, hasta el combatido Wagner, que ha concluido por ser la última y más sublime palabra de la creación musical. En los conciertos del año pasado [...] se iniciaban ya los procedimientos, la manera o el arte, lo que sea, el modo estupendo y maravilloso del autor del Ocaso de los Dioses. Ahora, este año, sin olvidar a los castizos clásicos, se nos van a dar lecciones del álgebra superior de los sonidos, leyéndonos las páginas del gran maestro alemán, para que podamos pasarnos, con conocimiento de causa, al wagnerismo, que partido o escuela, llena el mundo del arte [...] realizan, por tanto, una obra educadora, que honra a Murcia ${ }^{66}$.

Nuevamente estos “jóvenes músicos” encabezados por Enrique Martí ofrecen cinco conciertos, incorporando obras de Bizet, Weber, y la muerte de Sigfrido ${ }^{67}$ entre otras. Al igual que en el primer año, la Sociedad Murciana de Conciertos Clásicos anuncia un último concierto con obras de un único autor, en este caso no dedicado a Beethoven, sino a Chapí, fallecido en el mismo año 1909.

Aunque el protagonismo de esta etapa viene marcado por la interpretación (en formato instrumental, no vocal) de Wagner, la prensa sigue dando cuenta y alimentando la campaña a favor del músico, aunque no con la virulencia de la primera etapa. La mayoría de noticias aparecidas en relación al compositor, tienen que ver más con la curiosidad y lo anecdótico, como el anuncio de un libro-guía de audición de las óperas de Wagner o las estadísticas sobre los derechos de autor que éstas proporcionan ${ }^{68}$. Sin embargo, encontramos cuatro textos interesantes por cuanto reflejan el estado de la cuestión, no solo en Murcia sino fuera de ella. El primero, de 1903, está firmado por Antonio Cortón, y relata su audición en el Liceo de Barcelona de Lohengrin; el periodista coloca a la misma altura el Lohengrin y La Bohème, considerando así que el arte de Wagner se ha vulgarizado, criticando sarcásticamente la posición del público frente a esta música, especialmente del público femenino ${ }^{69}$. En 1908 aparece otra reseña operística,

66 Cf. El Liberal, 3 de abril de 1909

67 Gran impresión causó esta página musical de Wagner: "es tal la belleza de este fragmento de la obra wagneriana, es tanta su apasionada intensidad que al oírlo produce una íntima, una penetrante emoción, que nos lleva, por un fenómeno de verdadera sugestión a participar de aquel luto solemne y a llorar el triste fin de Sigfrido, el héroe de la leyenda teutónica. Los profesores del Sexteto, interpretando esta dificilísima obra musical, estuvieron acertadísimos y el público, dominado por la portentosa creación de Wagner, demostró su entusiasmo aplaudiendo hasta el punto de hacer repetir todo el número" Cf. El Tiempo, 20 de abril de 1909

68 La publicidad sobre el libro comenzaba afirmando que "los nombres de La Walkiria, Sigfrido, Wotan con su acompañamiento de dioses, héroes, ondinas y nibelungos, se escuchan pronunciados con frecuencia cada vez mayor. La gran Tetralogía de Wagner va siendo conocida y apreciada con creciente interés" Cf. El Diario de Murcia, 20 de febrero de 1902; para las estadísticas sobre los ingresos, Vid. El Diario de Murcia, 14 de enero de 1903.

69 'Mientras exista Lohengrin y esta obra 'se eche', el bello sexo aristocrático, con sombrero o sin él, poblará las localidades de lujo [...] casi todas las españolas se han convertido en un instante a la religión de Bayreuth... ya sé bien que hay en la cantidad un montón de amables señoritas a quienes Fafner, el Dios Loge, Elsa y Lohengrin suelen inspirar, a lo sumo, una magnífica indiferencia. Pero es también respetable el número de las sinceras y convencidas. Una amiga mía que tiene el talento de conservar toda su ingenuidad de impresión, preguntándole yo el otro día por qué gusta de Wagner, me contestaba: "porque me recuerda mi primera comunión"” Cf. El Liberal, 5 de diciembre de 1903 
en este caso en otro escenario, el del Teatro Real, y de otra obra, La Walkiria, cantada en alemán, con elenco alemán, y que sirve al crítico para afirmar que el público del Real es entendido, salvo el público de palcos y plateas ("ministro La Cierva a la cabeza") que pasa la ópera leyendo el argumento: "aquí no tiene la 'gente' más que el argumento abominable que venden a la puerta del teatro. Y cuando con solo esto, óperas como La Walkiria, entusiasman, ¿qué decir de los que todavía declaran a Wagner de lo más insoportable?"70. El tercer texto que consideramos interesante es un fragmento titulado Consideración social de la música, firmado por Felipe Pedrell y publicado en El Liberal el 2 de diciembre de 1905. Por último, creemos pertinente detenemos en los comentarios de Antonio Rubio al escuchar el Quijote de Strauss en Londres:

No puede compararse a Wagner con Strauss. En Wagner no hay detalle ocioso. Todo va al fin que el autor se propone; todo es un ornamento para la idea capital [...] había oído cantos de Strauss y cosas para orquesta que me parecieron admirables, pero que me dieron la impresión de un Wagner disminuido, de un músico de mucho talento y saber, pero sin mucha personalidad. Pero Don Quijote me hizo vibrar y olvidar tan en absoluto mis prejuicios que no me dio tiempo a pensar en ellos ${ }^{71}$.

A las alturas de 1910 parece, por tanto, que la batalla se ha librado y Wagner ha salido victorioso. Sin embargo, un texto de 1908 firmado por Chevalier nos muestra un punto de vista bien distinto: "causa verdadera tristeza el pensar que en una población como la nuestra no podamos oír compañías de ópera más que muy de tarde en tarde" ${ }^{72}$. Tras elogiar la labor de la Sociedad de Conciertos ${ }^{73}$, y criticar duramente a las bandas con su "habanera del Pon-pon o los cuplés de Toribio" (sin culpar a los músicos, sino al público que exige ese repertorio), Chevalier reflexiona ante la inminente temporada de ópera:

¡Cuidado que se desconocen en Murcia óperas que se ponen en todas partes! Pues bien, en el repertorio no se ve ni una [...] Lo conocido, lo que hemos oído cantar a todas las compañías que han venido, lo que cantan ya todos los gramófonos. ¿Es que no hay otro repertorio más nuevo? ¿Es que no veremos nunca en Murcia el Sansón y Dalila de Saint-Saëns, que se pone en todas partes? ¿Es que no tenemos derecho a conocer el Tannhäuser, el Sigfrido o alguna otra obra del gran maestro alemán? No. Decididamente no salimos del camino trillado. ¡Ah!, y gracias ${ }^{74}$.

70 Cf. El Liberal, 27 de febrero de 1908

71 Cf. El Liberal, 20 de febrero de 1906. Al copiar las palabras del violoncelista murciano, el redactor destaca que han sido recogidas por Ramiro de Maeztu por su interés.

72 Cf. El Tiempo, 19 de octubre de 1908

73 "Gracias a la buena voluntad de unos cuantos músicos se organizaron no hace mucho tiempo unos conciertos en que pudimos oír algo de lo muchísimo bueno que por aquí no conocemos; pues bien, a pesar del sacrificio que se impusieron los organizadores, a pesar de la reconocida competencia de los ejecutantes, a pesar de los magníficos programas y a pesar de la baratura inconcebible de los precios, casi fueron un fracaso, porque en una población de más de treinta y dos mil habitantes, que asistieran cien o doscientas personas, si asistieron, a cada concierto, lo demuestra". Cf. El Tiempo, 19 de octubre de 1908

74 Loc. Cit. 
En efecto, desde el estreno en 1899 de Lohengrin, ésta es la única ópera de Wagner que se representa (y dentro del repertorio italiano y francés) en las temporadas del Teatro Romea. Por desgracia, Chevalier no vería cumplido su sueño de ver representadas las óperas de Wagner en el teatro; sin embargo, sí pudo, en los años siguientes, escuchar los fragmentos del compositor, si bien no en escena, sí en formato orquestal.

\section{CONCIERTOS DE LA ORQUESTA SINFÓNICA EN MURCIA (1910-1922)}

El precedente inmediato de los conciertos de la Orquesta Sinfónica de Madrid en Murcia se sitúa en 1909, año en el que la Banda Municipal de Madrid es invitada a Murcia por la Federación de Gremios, dentro del "Certamen de la Virtud y del Trabajo". La expectación por escuchar la agrupación musical es elevada; así lo demuestra el hecho de que sea recibida en la estación de trenes por una comisión de concejales y otras personalidades de la ciudad. Aunque en un principio, la Banda Municipal viene para ofrecer un concierto en la Plaza de Toros, parece que al final son cuatro (y aún cinco) los que ofrece: la crónica que destaca su llegada a la ciudad, justifica la presencia de numerosa gente en la Catedral, "al saberse que la banda iba a tocar en dicho templo"75, siendo éste el primero aunque, al parecer, de carácter improvisado; el primero de carácter oficial, se verifica en la plaza de toros el 5 de septiembre, con un programa dividido en dos partes, una primera con obras de Berlioz, Weber, Bretón y Wagner, y una segunda con obras de Fernández Caballero, Barbieri, Chabrier y Liszt ${ }^{76}$; a éste sigue el ofrecido en el Teatro Circo Villar el día siguiente ${ }^{77}$, donde la presencia de la música de Wagner aumenta:

Es la Entrada de los Dioses en el Walhalla [...] música de imponderable belleza y majestad y su interpretación por la banda madrileña fue perfecta [...] como digno final de tan selecto programa, la Banda de Madrid nos hizo oír la enorme obertura de Tannhäuser, una de las obras más grandes del coloso del drama lírico, del hoy ya indiscutible Wagner [...] El público, electrizado al llegar este final, levantose en masa y tributó a la Banda del Sr. Villa y al genio del gran Wagner una de las más grandes ovaciones que se registran en esta $\operatorname{ciudad}^{78}$.

75 Cf. El Liberal, 6 de septiembre de 1909. Sobre la Banda informa de que "se compone de 96 plazas; ostentan elegante uniforme estilo inglés, levita cerrada y gorra de plato". La Banda Municipal de Madrid estuvo dirigida, en sus conciertos en Murcia, por el maestro Villa.

76 El programa detallado es el siguiente: Primera parte: marcha de La condenación de Fausto (Berlioz), Invitación al Vals (Weber), En la Alhambra, serenata (Bretón), gran fantasía de La Walkiria (Wagner); Segunda parte: obertura de El primer día feliz. (Fernández Caballero), fantasía de Pan y toros (Barbieri), España, rapsodia (Chabrier), Rapsodia húngara $n^{o} 2$ (Liszt). Aunque la crónica señala que no hubo demasiada gente ("sin duda por aguardar al concierto en el teatro"), destaca el concierto como un acontecimiento artístico, con gran ovación para la pieza de Fernández Caballero (el compositor murciano había fallecido en 1906), indicando: "los espíritus cultivados pudieron admirar la grandiosa orquestación de la fantasía de La Walkiria. Los netamente españoles desbordaron sus corazones sentimentales y patrióticos con las cadencias de la serenata En la Alhambra y las valentías picarescas, chispeantes, llenas de calor y de luz y de sol español de la fantasía de Pan y toros". Cf. El Liberal, 6 de septiembre de 1909

77 El programa detallado es el siguiente: Primera parte: Oberón, obertura (Weber), bailable de Raimundo Lulie (Villa), Entrada de los dioses en el Walhalla (Wagner); Segunda parte: Suite (danza, allegro marcado, allegretto tranquilo, allegro moderato, allegro molto) de Grieg; Tercera Parte: obertura de Mignon (Thomas), Reverie (Saint-Saëns), obertura de Tannhäuser (Wagner).

78 Cf. El Tiempo, 7 de septiembre de 1909. Las audiciones wagnerianas se completarían en el tercer concierto de la Banda, ofrecido el 8 de septiembre en la plaza de toros, donde, junto a Coppelia de Delibes y obras de Bretón, Massenet, Barbieri y Bretón, se interpreta el preludio de Los Maestros Cantores. Cf. El Tiempo, 8 de septiembre de 1909. 
Dos conciertos más (día 7 de septiembre en la plaza de toros, y día 8 por la mañana en el Teatro Circo Villar) ofrece la Banda Municipal en Murcia, dejando un gratísimo recuerdo en el público: “doy la enhorabuena más sincera a la Federación de Gremios que pensando alto y sin temor alguno ha proporcionado a Murcia la ocasión de oír lo que sin su noble y hermosa iniciativa nos estaba vedado, quién sabe hasta cuándo, quizá hasta... nunca"79. Erraba el crítico en su juicio pesimista; tan solo unos meses después, la Orquesta Sinfónica de Madrid iba a empezar a ofrecer unos conciertos en Murcia de periodicidad anual que proporcionarían el acceso a un repertorio hasta entonces desconocido por la mayoría de los murcianos. La Banda Municipal supone el primer paso en este camino; la Orquesta Sinfónica la implantación definitiva.

En 1910 se produce la primera visita de la Orquesta Sinfónica del maestro Fernández Arbós a Murcia. El 7 de abril de 1910, El Liberal informa de las gestiones que se están llevando a cabo para atraer la agrupación musical a Murcia, añadiendo que, si finalmente se consigue la empresa, será una oportunidad para escuchar obras del maestro murciano Pérez Casas. Aunque en un principio se anuncia la actuación de la Orquesta en el Teatro Romea, finalmente ésta se realiza en el Teatro Circo Villar, donde los días 21 y 22 de abril se ofrecen dos conciertos con protagonismo en el programa de la obra wagneriana ${ }^{80}$; Emilio Ramírez (hijo de Antonio Ramírez) firma la crónica del primer concierto, destacando la impaciencia del público por escuchar a la Orquesta, y señalando, a propósito de Wagner:

En Los murmullos de la Selva, Wagner se sobrepuso [...] Pero donde el entusiasmo llegó a su mayor grado fue en esa página sublime que el colosal Wagner compuso para obertura de su ópera Tannhäuser. Se obligó a la orquesta a bisar la obra, se ovacionó al director y a los profesores, y el público, en una palabra, dio rienda suelta a su admiración ${ }^{81}$.

El entusiasmo se repite en el segundo concierto, siendo aún mayor si cabe, ya que, si en el primero la segunda parte estaba consagrada a Beethoven, en éste se destina a la presentación de A mi tierra de Pérez Casas en Murcia. Con el público entregado por tal ejecución, se cierra el programa nuevamente con Wagner, esta vez con la Cabalgata de las Walkirias, que "produjo el mismo delirio que en la noche anterior la obertura de Tannhäuser. Entre tempestades de bravos y palmadas se repitió la obra" ${ }^{\text {"2. }}$.

En 1911, y también en abril, vuelve la Orquesta Sinfónica a Murcia, ofreciendo, no dos, sino tres conciertos. La prensa se moviliza y calienta el ambiente ofreciendo datos biográficos de los compositores

79 Cf. El Tiempo, 8 de septiembre de 1909.

80 No es éste el lugar (y la tarea excede las dimensiones de este artículo) para destacar que la Orquesta Sinfónica de Madrid, además de proporcionar obras desconocidas de Wagner, dio oportunidad para conocer en Murcia otras obras contemporáneas de compositores como Tchaikovsky ( $5^{a}$ sinfonía, 1812), Borodin (En las estepas del Asia Central), Albéniz (Iberia), Dukas (El aprendiz de brujo), Berlioz (La condenación de Fausto, Sinfonía fantástica), Dvorak (Sinfonía del nuevo mundo), Debussy (Preludio a la siesta de un fauno), Rimsky-Korsakov (Scherezade) además de obras de clásicos como Bach, Beethoven, Haendel, Mendelssohn o Mozart.

81 Cf. El Liberal, 22 de abril de 1910. Emilio Ramírez no fue, al igual que su padre, un entusiasta wagnerista, y así lo manifestó en sus escritos y sus obras, caracterizadas por un regionalismo musical basado en el folklore murciano.

82 Cf. El Liberal, 23 de abril de 1910. 
y aspectos musicales de las obras ${ }^{83}$. J.P.M. (presumiblemente José Pérez Mateos) firma las crónicas de $E l$ Liberal invitado por el director del periódico: en la primera destaca la tercera parte del concierto, dedicada a Wagner con el preludio de Lohengrin, el Viaje de Sigfrido por el Rin y la obertura de Rienzi, indicando que, a su juicio lo más notable del concierto fue "la brillantísima página de El Ocaso de los Dioses"; en el segundo concierto, juzga como acertado remate del mismo la ejecución de la Cabalgata de las Walkirias, "grandioso, sublime fragmento de la segunda parte de El Anillo", que no por conocida (había sido la misma orquesta la que la había ofrecido al público en 1910) deja de ser acogida con ovaciones que obligan a su repetición; en el tercer concierto destaca como "las obras de la noche" las de Beethoven y Wagner; respecto a éste:

La ovación más inmensa que logró la Sinfónica fue al interpretar [...] la grandiosa obertura de Tannhäuser. El público cautivado, electrizado por el poderoso genio de Wagner, aplaudió loco de entusiasmo, cuando escuchó los últimos acordes, pidiendo su repetición [...] Las obras de Wagner han sido, como siempre, las que más han logrado levantar al público, entusiasmándole. No en balde, decía Bizet que la música de Wagner no era la música del porvenir, sino la música de todos los tiempos, porque es sencillamente admirable. Nuestro público ha sabido distinguir la música vulgar de la música sublime ${ }^{84}$.

En 1912 parece que la Orquesta Sinfónica no visita Murcia, sin embargo, en relación con la obra wagneriana, otro acontecimiento sucede en la ciudad: la visita de una compañía de ópera al Teatro Romea con la que actuará, en dos únicas audiciones, el "eminente tenor Francisco Viñas"85. Dicha compañía ofrecerá óperas de repertorio, entre las que se encuentra Lohengrin, además de estrenar Madame Butterfly de Puccini. En 1914, volveremos a ver Lohengrin en la cartelera de Romea; y no será la única ocasión en que los murcianos podrán escuchar a Wagner cantado: en 1913, en un concierto en el que participan Antonio Puig y José del Hierro, el tenor murciano Javier Bojart canta El canto d'amore de La Walkiria, y aún en

83 Así, se ofrecen datos de Cherubini y Borodin, pero no se dan de Beethoven y Wagner, ya que por ser "tan populares y conocidos" no se quiere "ofender la cultura de nuestros lectores repitiendo una vez más la historia y la labor de tan geniales maestros". Cf. El Liberal, 26 de abril de 1911.

84 Para la crítica del primer concierto Vid. El Liberal, 27 de abril de 1911. Para el segundo, Vid. El Liberal, 28 de abril de 1911. Para la del tercero, Vid. El Liberal, 29 de abril de 1911. El texto de Bizet al que se refiere el crítico había sido publicado por El Liberal el 28 de enero de 1910, aunque no con el tono laudatorio que éste lo refiere. Respecto a la "elección de la música sublime" por parte del público, baste decir que la exigencia musical de éste es muy superior a la mostrada en otras épocas; así, al comentar la actuación de la banda de música del maestro Rojales, apreciando toda su labor, se señala una "temeridad" por su parte acometer la interpretación de obras de Wagner: "Hay que cuidarse de no profanar a Wagner..." Cf. El Liberal, 17 de agosto de 1911. La ejecución de la Cabalgata de las Walkirias durante el segundo concierto provocó la aparición de un entusiasta artículo firmado por Pascual de Ayala con el mismo título en El Liberal, el 30 de abril de 1911.

85 Cf. El Liberal, 3 de marzo de 1912. Francesc Viñas fue el gran intérprete de las óperas wagnerianas en la época, no solo en España: su papel más conseguido fue el de Lohengrin, que solo en sus tres primeros años de carrera, cantó 120 veces, y con el que alcanzó tal fama que el káiser Guillermo II lo calificó como el mejor intérprete de esta ópera tras escucharlo en Nápoles. En 1893 cantó Tannhäuser en Covent Garden y, a partir de esta época, publicó diversos artículos (al igual que Padilla) sobre la obra wagneriana. En 1913 consiguió una de sus principales metas, al estrenar Parsifal en el Teatre del Liceu de Barcelona, motivo por el cual se le dedicó una placa en el coliseo de las Ramblas. 
1914, en una función a beneficio del citado Bojart, éste interpreta el raconto de Lohengrin $^{86}$. Wagner parece que ha ganado definitivamente la batalla en Murcia: en los Juegos Florales de 1912, el mantenedor, Rodríguez Valdés, dedica su discurso a la obra wagneriana, en la prensa se suceden los textos referidos a cualquier novedad o curiosidad relativa a la obra del compositor, se ejecuta en formato instrumental o vocal ${ }^{87}$, y hasta encontramos en confiterías bombones y caramelos que llevan los nombres de "Wagner, Lohengrin, Sigfredo o Walkiria"88.

En 1913 vuelve la Orquesta Sinfónica de Madrid, de nuevo bajo la dirección de Fernández Arbós a dar dos conciertos en Murcia. La prensa prepara el ambiente días antes, indicando que se estrenarán dos obras de autores españoles, Joaquín Turina (La procesión del Rocío) y Oscar Esplá (El sueño de Eros). Finalmente, solo se estrena la obra de Turina en unos conciertos en los que figuran el preludio y $L a$ muerte de Iseo de Tristán e Isolda, el preludio de Los Maestros Cantores y la Obertura de Tannhäuser. Estas obras como anunciadas, pues por la crónica del segundo concierto sabemos que, ante el entusiasmo despertado por la Obertura de Tannhäuser (pieza programada para cerrar el programa) la orquesta ejecutó Los murmullos de la selva, obra fuera de programa ${ }^{89}$.

Oscar Esplá será incluido (con su poema sinfónico Poema de niños) en los conciertos del año 1914, en los que también se programa el poema sinfónico Muerte y transfiguración de Strauss. Respecto al repertorio wagneriano, encontramos el preludio de Parsifal, el preludio y La muerte de Iseo de Tristán e Isolda y la marcha fúnebre del Ocaso de los Dioses; éstas en programa, pues al término Arbós "regala" la Cabalgata de las Walkirias $^{90}$. Respecto al segundo concierto, la atención se centra en la obra de Strauss, gustando mucho la de Esplá y, aún más, todo el repertorio wagneriano. Parece existir en esta época una

86 Para el concierto del año 1913 Vid. El Tiempo, 24 de mayo de 1913; para la función a beneficio de Bojart, Vid. El Tiempo, 14 de diciembre de 1914.

87 Aunque la labor más destacada es la de la Orquesta Sinfónica de Madrid, la vida musical murciana, en forma de bandas y sextetos, continúa con la campaña wagneriana: así, entre otras obras, la Banda del Regimiento de Sevilla ejecuta la sinfonía de Rienzi (Vid. El Liberal, 16 de septiembre de 1911) y la Banda de la Misericordia una fantasía sobre El anillo del Nibelungo (Vid. El Tiempo, 13 de febrero de 1915); por su parte, Antonio Puig sigue ofreciendo sus conciertos en el Café Oriental (en los que ofrece a un tiempo fragmentos de Parsifal y de Maruxa de Vives) o en el Círculo Católico, donde en un homenaje a la memoria de Menéndez Pelayo se ejecuta la Marcha fúnebre de Tannhäuser (Vid. El Tiempo, 1 de junio de 1912) o donde, al inaugurar el curso 1919, Puig diseña un programa en el que figuran Tannhäuser, el Largo de Haendel, Los encantos del Viernes Santo de Parsifal y Alborada de Fernández Caballero (Vid. El Tiempo, 11 de enero de 1919).

88 Algunos textos referidos a Wagner son los dedicados a La bailarina desnuda, en alusión a Isadora Duncan, firmado por Antonio G. de Linares (Vid. El Liberal, 1 de enero de 1912), la poesía homenaje firmada por Tirso Camacho (Vid. El Tiempo, 19 de febrero de 1913) o Parsifal, poema vegetarianista, de Enrique Gómez Carrillo (Vid. El Liberal, 23 de febrero de 1914). Respecto a las anécdotas, la prensa murciana da cuenta de la subasta en Berlín de un pañuelo regalo de boda a Wagner (Vid. El Liberal, 24 de abril de 1910), del pleito sobre si Iseo y Sigfrido son hijos legítimos de Wagner (Vid. El Tiempo, 28 de abril de 1914) o de las disputas entre Cósima e Isolda por la herencia de Wagner (Vid. El Liberal 29 de mayo de 1914). Sobre las representaciones, se sigue con interés la de Parsifal en París o de la tetralogía wagneriana en Nueva York; uno de los textos más interesantes es el referido, firmado por Marsillach, a la crisis económica del Liceo, que provoca la sustitución de Parsifal en la cartelera por El Barbero de Sevilla y, posteriormente, por Marina de Arrieta: "La Wagneriana ha quedado en ridículo y por los suelos nuestra fama de ser los únicos españoles inteligentes en música. ¡Lo que en Barcelona se hubiera dicho si en el Real llegan a retirar las óperas de Wagner para ceder el punto a la de Arrieta!" Cf. El Liberal, 15 de diciembre de 1914.

89 Cf. El Tiempo, 5 de mayo de 1913. La crónica está firmada por E. M., presumiblemente, Enrique Martí. Para el anuncio de la obra de Turina Vid. El Tiempo, 4 de abril de 1913; para la de Esplá, Vid. El Tiempo, 8 de abril de 1913.

90 Cf. El Tiempo, 10 de junio de 1914. El crítico, en su crónica, aprovechaba para animar la expectación ante el segundo concierto: "el segundo concierto, anunciado para esta noche, es esperado con vivísima expectación. Realmente es trascendental. Los nombres de Bach, Beethoven, Wagner, Mendelssohn y Strauss figuran juntos. ¿Se puede exigir más?” 
norma no escrita por la que los conciertos de la Sinfónica en Murcia finalizan siempre con obras de Wagner: así, si en el primer concierto se había improvisado la Cabalgata de las Walkirias, en el segundo, que debía concluir con 1812 de Tchaikowsky, a pesar del "notable efecto que produjo en el público", se añade la obertura de Tannhäuser, que provoca tal entusiasmo en el público que "estuvo largo tiempo ovacionando a Wagner, a Arbós y a los prodigiosos profesores de esa Gran Orquesta"91.

El año 1915 trae como novedad la teorización y difusión de Wagner de nuevo desde la intelectualidad. En este caso, es José Perez Mateos quien, "a virtud de la próxima visita a Murcia de la Orquesta Sinfónica" pronuncia una conferencia en la Federación de Dependientes de Comercio y Banca sobre Filosofía del Arte Wagneriano ${ }^{92}$. Aún más novedades encontramos en los programas de los conciertos de la Orquesta Sinfónica: nuevamente Strauss (en esta ocasión, el Don Juan) y, por supuesto, Wagner, aunque con nuevo repertorio: El jardín encantado de Klingsor y Los encantos de Viernes Santo de Parsifal, Bacanal de Tannhäuser y Despedida de Wotan y Fuego encantado de La Walkiria. Respecto a Parsifal, es escuchado "con beatífica delectación y recogimiento", pues "Wagner ya es amigo de todos, ya se ha metido en el corazón del pueblo, dominándolo con su avasalladora arrogancia y con su imponente señorío. Ya le amamos todos como a una caricia de un héroe"93.

Los dos conciertos del año 1916 se trasladan de abril a octubre. En el programa vuelven a figurar Beethoven (Sexta sinfonía), Granados (Goyescas y Danzas españolas), Strauss, autores rusos, y Wagner, con Los encantos del Viernes Santo (Parsifal), la marcha fúnebre (El ocaso de los Dioses) y el Idilio de Sigfried. El crítico de El Tiempo, oculto bajo el pseudónimo Sigfredo, considera el programa un acierto ${ }^{94}$, y, refiriéndose a Wagner, y bautizándose a sí mismo Sigfredo, sus palabras no pueden ser más elogiosas: "De Wagner no podemos comentar nada. Wagner se resiste al comentario. En él hay que creer. Pese a

$91 C f$. El Liberal, 11 de junio de 1914. Respecto a la obra de Strauss, hay que señalar que encuentra las mismas reticencias que Wagner en los inicios; así, en 1910, podíamos leer a propósito de Salomé en Madrid: "con Wagner ya vamos transigiendo, pero el amigo Strauss se ha traído una partitura que excluyendo a media docena que lo entienden de veras y a un par de docenas que dicen que lo entienden por dárselas de inteligentes, a los demás que presenciamos el estreno, nos pareció un latazo enorme" (Cf. El Tiempo, 21 de febrero de 1910). Respecto a la obra ofrecida por la Sinfónica en 1914, mientras para el crítico de El Tiempo, "apenas llegó a emocionar y reveló sus bellezas de un modo confuso e incompleto" (Cf. El Tiempo, 11 de junio de 1914), para el de El Liberal, "su música es vibrante, cauta y polícroma", saliendo de sus notas "el genial continuador de la obra wagneriana [...] puede definirse a Strauss diciendo que es un Wagner redivivo". También trae a colación a Wagner el crítico al hablar de Esplá: "Oscar Esplá es un enamorado de Wagner, sin que esto quiera decir que siga sus huellas" (Cf. El Liberal, 11 de junio de 1914).

92 A pesar del loable esfuerzo de Pérez Mateos por dar a conocer la obra wagneriana, por los fragmentos reseñados en la prensa murciana sobre su conferencia (Cf. El Liberal, 26 de abril de 1915), su discurso se asemeja en exceso (encontrando las mismas ideas expresadas del mismo modo) al del Dr. Letamendi en La música del porvenir y el porvenir de mi patria, texto del año 1884 y publicitado por La Época, la associació wagneriana, y reimpreso en Madrid en 1907 en sus obras completas.

93 Cf. El Liberal, 27 de abril de 1915. Comentarios elogiosos también hacia la obra de Strauss y de un autor querido en Murcia por su María del Carmen, Enrique Granados, también en programa con sus Danzas españolas. De todos modos, como incidiría el crítico de El Liberal en el segundo concierto, "la nota dominante fue Wagner, que reveló como siempre con toda su intensidad viril, con toda la gama infinita que no pudo escribir cerebro alguno sino el del coloso maestro". "Olímpico", "Dios", "Emperador" son algunos de los adjetivos con que lo califica el crítico antes de informar del regalo de Arbós, Los murmullos de la selva, fuera de programa, "que nos dejó pletóricos de arte y de poesía musical" Cf. El Liberal, 28 de abril de 1915.

94 "El programa que anoche se nos ofreció era un verdadero acierto. Obras todas ellas de fácil comprensión y bastante acomodadas a los gustos de nuestro público [...] un público provinciano, con el que no se puede pretender que acuda con entusiasmo a un espectáculo en que se le ofrecen obras muy superiores a su entendimiento, que en vez de emocionarle y atraerle, le aburren y apartan del terreno del arte. Anhelamos el progreso de nuestro pueblo en el orden cultural, pero este progreso no puede alcanzarse con procedimientos revolucionarios sino mediante una razonada evolución [...] el programa de anoche, repetimos, era un acierto" Cf. El Tiempo, 13 de octubre de 1916 
sus detractores, su música eminentemente melódica está impregnada de un acento de grandiosidad que levanta y nos arrebata, haciéndose dueño absoluto de nuestra voluntad"95.

En 1917 la Orquesta Sinfónica de Madrid cede el puesto, con gran placer para los murcianos, a la Orquesta Filarmónica de Madrid que, bajo la dirección de Pérez Casas, ofrece dos conciertos los días 17 y 18 de mayo en Murcia. Pérez Casas confecciona un programa en el que figuran Debussy, Mendelssohn, Cesar Franck,... y la Suite en La de Julio Gómez, Goyescas de Granados y su suite A mi tierra, algo que destaca la prensa: "figuran notables obras de autores insignes extranjeros, pero sin escatimar gusto a los españoles; siempre hemos echado de menos en los conciertos de la Sinfónica obras de nuestros españoles, que tienen derecho a figurar en los conciertos más selectos" ${ }^{\$ 9}$. El comentario no está exento de importancia pues, a partir de este momento, la presencia de Wagner va a decrecer notablemente: en el concierto de Pérez Casas, solo una pieza, y de sobra conocida, Los encantos del Viernes Santo de Parsifal. Y aunque, en 1921, cuando la Sinfónica visite de nuevo la ciudad, programe la Bacanal de Tannhäuser, el Viaje de Sigfrido por el Rin de El Ocaso de los Dioses, y dos fragmentos de Los Maestros Cantores, salvando las alabanzas a la pieza de El Ocaso, el crítico de La Verdad, indicará a Arbós:

Y perdóneme el ilustre Director de la Sinfónica: una advertencia para terminar. Las obras que más entusiasmo han despertado en este público han sido precisamente las de música española, que han recogido el ambiente popular: Triana de Albéniz, Goyescas de Granados y La Dolores de Bretón. ¿No podría servir esto de estímulo al ilustre Arbós para en años sucesivos, componer los programas con el mayor número posible de obras españolas? ${ }^{97}$

La época, por tanto, es distinta, y el movimiento wagneriano ha sido superado y olvidado. Así se desprende de la indiferencia reflejada en la crítica a los conciertos de la Filarmónica en 1922, en contraste radical con la pasión que había dominado las críticas de años anteriores ${ }^{98}$. A modo anecdótico, encontramos un texto del periodista y literato Sánchez Madrigal, a propósito de Lucia di Lamermoor, en el que ensalza la escuela belcantista: “¿Podrá darse mayor aberración que querer ridiculizar la afición al bel canto? ¿Pues habría de gustarnos el feo? ¡Ah! Si la moda no sellase muchos labios; [...] si se votase, no nominalmente, sino por bolas blancas y negras, ¡qué derrota más parecida a la de los agravios la de la ópera wagneriana!" 99 .

El año siguiente a este texto, en 1923, aparece en el suplemento de La Verdad un artículo del que había sido eminente impulsor del movimiento wagneriano, Enrique Martí, titulado La música en Murcia:

95 Loc. Cit.

96 El Liberal, 12 de mayo de 1917

97 Cf. La Verdad, 10 de mayo de 1921

98 "Wagner figuró en el programa con Los encantos de Viernes Santo y Los murmullos de la selva, ambas obras ya conocidísimas de todos". Frente a esto, se ensalza la música rusa (que compone la mayoría del programa), "esa música pasional que se extiende considerablemente", la obra de Beethoven ("música imprescindible"), A mi tierra de Pérez Casas e incluso el preludio de La revoltosa.

99 Cf. La Verdad, 17 de febrero de 1922. Resulta anecdótico el fragmento por cuanto Antonio Ramírez, en 1890, al atacar las óperas wagnerianas, también había recurrido a la Lucia de Donizetti. 
"en Murcia hay muy pocos músicos y muy escasa afición a gustar los deleites y fascinaciones del divino arte". El texto delata la frustración y apatía del músico; muy lejos queda la pasión y vehemencia de los comentarios sobre la representación de Lohengrin o los conciertos de la Sinfónica. El momento, como el propio Martí advierte, es ya otro muy distinto:

Los teatros cerrados, los cafés sin concierto,... No ha habido en estos cuatro meses en la sexta capital de España otras armonías, que las del viento en las ramas, la chirriante canturia de los grillos en la oscuridad, y el murmurio monótono del padre Segura... [...] es una lamentable verdad... Aquí no apasiona la música. A este propósito, recuerdo entre las brumas de mi niñez las controversias, disputas y aún riñas que se suscitaban entre los partidarios de las bandas de D. Emilio Raya y D. Ángel Mirete. ¡Inocente pugilato en tiempos románticos!, ¡Idos para no volver! [...] Esta atonía, este soplo de desamor pasará con las penurias de la época [...] Esperemos que las circunstancias, mediante una hábil y sugestiva modulación, la transporten bien pronto a tono brillante... ${ }^{100}$

\section{CONCLUSIONES}

El movimiento wagneriano en Murcia tuvo una importante presencia en una época y un tiempo en que se reclamaba para la ciudad una modernización, un progreso cultural y artístico, basado en una mirada al pasado (como construcción de una identidad regional) y una esperanza en el futuro. En este sentido deben entenderse las primeras campañas propagandísticas. Como en tantos otros lugares, Wagner no se "escucha" de un modo natural, sino, en cierto modo, provocado. En Murcia, los primeros impulsores de la música de Wagner son Julián Calvo, Joaquín Payá y Mariano Padilla, que defienden la obra wagneriana, sin que haya una vinculación de ésta a una ideología regionalista o nacionalista: sencillamente muestran, describen, y ofrecen esa nueva música que todo el mundo "debe" conocer. Frente a ellos, Antonio Ramírez y Andrés Blanco desconfían de la nueva música, considerándola dura y complicada. Más allá de las polémicas periodísticas, estos primeros tiempos están marcados por el desconocimiento de la obra wagneriana. Se habla mucho, pero se "escucha" poco o nada, y lo que se escucha es a través de los relatos sobre los estrenos europeos y madrileños. La situación cambiará con la representación de Lohengrin en el Teatro Romea, en abril de 1899.

La posibilidad de presenciar en escena la obra de Wagner no solo provocó que antiguos detractores (como Antonio Ramírez) se "convirtieran" a la "nueva religión", sino que permitió que jóvenes músicos de la ciudad se apasionaran con el arte de Bayreuth. Éstos serían los que permitirían seguir escuchando la obra wagneriana, a través de sus conjuntos de cámara que actuaron en hoteles, cafés y centros de sociabilidad de la ciudad. Sus acciones cristalizaron en la creación de la "Sociedad Murciana de Conciertos". Junto a Puig, Martí y Marín, hay que reseñar igualmente la labor de las bandas de música.

100 Suplemento de La Verdad, 1 de enero de 1923 
A pesar de los esfuerzos, hasta el año 1910 apenas se habían escuchado en Murcia fragmentos de las óperas de la segunda y tercera época del compositor. El repertorio habitual (Rienzi, Lohengrin, Tannhäuser) se amplió gracias a la labor de la Orquesta Sinfónica de Madrid, bajo la dirección de Fernández Arbós. Con las visitas anuales de la agrupación musical no solo se conoció (aunque en formato sinfónico) la obra de Wagner (Sigfrido, Ocaso de los Dioses, Parsifal,...), sino que se consolidó el wagnerismo en Murcia. La prensa se mostraba entusiasta, todos los conciertos debían finalizar con una obra de Wagner que, merced a los aplausos y ovaciones, debía ser repetida. La conquista se había realizado y el público murciano se definía wagneriano.

A partir de 1917 comenzó a notarse un cambio en la estética imperante, que se deslizó desde la música germánica a la música rusa y, muy especialmente, a la música española. Prensa y público reclamaban obras (de marcado sabor regionalista) de autores españoles (Pérez Casas, Bretón, Granados,...) desapareciendo la pasión y el culto hacia Wagner, pudiendo considerarse el movimiento prácticamente extinguido en los años veinte.

Recibido: 28/09/2010

Aceptado: 30/11/2010 